\title{
A successful antimicrobial regime for Chromobacterium violaceum induced bacteremia
}

\author{
James I Campbell ${ }^{1}$, Nguyen Phu Huong Lan², Phan Tu Qui ${ }^{2}$, Le Thi Dung ${ }^{2}$, Jeremy J Farrar ${ }^{1}$ and Stephen Baker ${ }^{1,3^{*}}$
}

\begin{abstract}
Background: Chromobacterium violaceum is a proteobacterium found in soil and water in tropical regions. The organism rarely causes infection in humans, yet can cause a severe systemic infection by entering the bloodstream via an open wound.

Case presentation: We recently identified a case of severe bacteremia caused by Chromobacterium violaceum at the Hospital for Tropical Diseases (HTD) in Ho Chi Minh City, Vietnam. Here, we describe how rapid microbiological identification and a combination of antimicrobials was used to successfully treat this life threatening infection in a four-year-old child.

Conclusions: This case shows the need for rapid diagnosis when there is the suspicion of a puncture wound contaminated with water and soil in tropical regions. We suggest that the aggressive antimicrobial combination used here is considered when this infection is suspected.
\end{abstract}

\section{Background}

Chromobacterium violaceum is a Gram-negative facultatively anaerobic proteobacterium that can be isolated from water and soil in tropical and sub-tropical regions [1]. The organism rarely infects humans; yet, occasionally, the organism can establish a severe systemic infection by entering the bloodstream via an open wound. There has been a recent surge in interest in human Chromobacterium violaceum infections in South East Asia, potentially as a consequence of increased reporting and awareness [2]. In 2008 we documented the first ever case in Ho Chi Minh City [3]. Since this primary case, three more infections have been observed in the city hospitals. Due to the rapid progression of human Chromobacterium violaceum infections, a systemic infection with this bacterium is typically fatal and no efficacious treatment regimes have ever been described. Here we report a case of Chromobacterium violaceum in Ho Chi Minh City that was successfully treated with a combination of antimicrobials.

\footnotetext{
* Correspondence: sbaker@oucru.org

${ }^{1}$ The Hospital for Tropical Diseases, Wellcome Trust Major Overseas Programme, Oxford University Clinical Research Unit, Ho Chi Minh City, Vietnam

${ }^{3}$ The London School of Hygiene and Tropical Medicine, London, UK Full list of author information is available at the end of the article
}

\section{Case presentation}

A four-year-old HIV negative male presented at the Hospital for Tropical Diseases in Ho Chi Minh City with a puncture wound on his right ankle. He was admitted and had a three-day history of fever, fatigue, vomiting and anorexia. He had previously been diagnosed with pulmonary Tuberculosis when three years old and had previously been taking a combination of rifampicin, 4-aminosalicylic acid and ethambutol for eight months. He had no other underlying diseases. On admission he had a pulse rate of 180 beats/minute, low blood pressure, a respiration rate of 57 breaths/minute, crackling chest sounds and pale sclera. The cervical lymph nodes were swollen, measuring $2 \mathrm{~cm}$ in diameter. He had displayed evidence of hepatomegaly, but was not jaundiced and had two small blisters on the abdomen.

The initial clinical diagnosis was acute sepsis. An antimicrobial regime of $200 \mathrm{mg} /$ day of amikacin, $150 \mathrm{mg} /$ day of vancomycin and $1.25 \mathrm{~g} /$ day of ceftriaxone was initiated immediately. On admission, the hematology results showed a normal white blood cell count with low hemoglobin (Table 1). The blood chemistry was also unremarkable (Table 2), apart from a $\mathrm{C}$ reactive protein concentration of $312 \mathrm{mg} / \mathrm{l}$ (normal range 0-5 mg/l), indicating severe sepsis. Radiography showed new pulmonary infiltrations, yet this was deemed not to be consistent with a progression of
C Biomed Central

(c) 2013 Campbell et al.; licensee BioMed Central Ltd. This is an Open Access article distributed under the terms of the Creative Commons Attribution License (http://creativecommons.org/licenses/by/2.0), which permits unrestricted use, distribution, and reproduction in any medium, provided the original work is properly cited. 
Table 1 Hematology results over Chromobacterium violaceum infection

\begin{tabular}{lccccc}
\hline Days $^{{ }^{2}}$ & WBC $(\mathrm{K} / \mu \mathrm{L})$ & \% Neutrophils & Haemoglobin $(\mathbf{g} / \mathbf{d L})$ & Platelets $(\mathrm{K} / \boldsymbol{\mu l})$ & C-reactive $\mathbf{p r o t e i n}(\mathbf{m g} / \mathbf{l})$ \\
\hline 1 & 8.96 & 77.8 & 11 & 154 & 312 \\
2 & 9.26 & 83.4 & 14 & 61 & 298 \\
3 & 8.36 & 84 & 12.8 & 40 & 241 \\
5 & 4.14 & 57.8 & 11.6 & 50 & 107 \\
6 & 7.85 & 55.6 & 11.4 & 81 & 93 \\
10 & 14.7 & 62.7 & 9.6 & 592 & 67 \\
12 & 12.85 & 76.9 & 7.4 & 590 & 51 \\
17 & 14.93 & 69.5 & 11.9 & 635 & 48 \\
18 & 12.37 & 56.7 & 12.2 & 527 & 16 \\
\hline
\end{tabular}

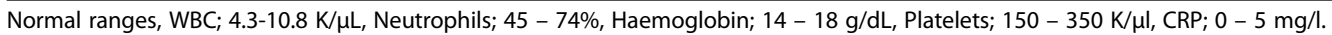

${ }^{a}$ Days post admission.

tuberculosis, a sputum smear was negative and further smears from a stomach aspirate and bronchial fluids were also negative. A blood sample was taken and inoculated into a Peds Plus/F BACTEC bottle and incubated at $37^{\circ} \mathrm{C}$ in an automated BACTEC 9240 machine (Becton Dickinson, United Kingdom). After 24 hours a positive result was recorded, and a Gram-negative bacilli was identified. Subcultures were performed on blood agar and nutrient agar plates and incubated aerobically at $35^{\circ} \mathrm{C}$. After overnight incubation the agar plates demonstrated numerous small colonies with a dark violet metallic pigmentation. This pigmentation is unique to Chromobacterium violaceum, differentiating the organism from other tropical, soil dwelling organisms, and is due to the production of a chemical called violacein [4]. Identification of Chromobacterium violaceum was confirmed by a positive mannitol test and API 20NE [3]. The bacterial isolate was tested for susceptibility to a range of antimicrobials (cefapine, ciprofloxacin, amikacin, ofloxacin, imipenem, ceftriaxone, ceftazidime and piperacillin/tazobactam) on Mueller-Hinton agar, and interpreted according to the CLSI guidelines for non-Enterobaceriaceae Gram-negatives [5]. The phenomenon of intrinsic antimicrobial resistance

Table 2 Blood chemistry results of a Chromobacterium violaceum infection on admission

\begin{tabular}{lc}
\hline Chemical test (normal range) & Result \\
\hline Sodium $(135-145 \mathrm{mmol} / \mathrm{l})$ & $130 \mathrm{mmol} / \mathrm{l}$ \\
Potassium $(3.5-5.0 \mathrm{mmol} / \mathrm{l})$ & $3.15 \mathrm{mmol} / \mathrm{l}$ \\
Chlorine $(98-106 \mathrm{mmol} / \mathrm{l})$ & $84.8 \mathrm{mmol} / \mathrm{l}$ \\
Calcium $(2.15-2.6 \mathrm{mmol} / \mathrm{l})$ & $2.09 \mathrm{mmol} / \mathrm{l}$ \\
Creatinine $(53-130 \mathrm{\mu mol} / \mathrm{l})$ & $103 \mu \mathrm{mol} / \mathrm{l}$ \\
SGPT $(0-40 \mathrm{UI} / \mathrm{l})$ & $22 \mathrm{UI} / \mathrm{l}$ \\
GGT $(7-50 \mathrm{UI} / \mathrm{l})$ & $24 \mathrm{UI} / \mathrm{l}$ \\
Lactate IV $(0.6-2.4 \mathrm{mmol} / \mathrm{l})$ & $5.28 \mathrm{mmol} / \mathrm{l}$ \\
\hline
\end{tabular}

in Chromobacterium violaceum is well described [6]. However, this isolate did not exhibit comprehensive resistant to any of the tested antimicrobials. On day three the antimicrobial therapy was changed to $330 \mathrm{mg} / 8$ hours of meropenem, $150 \mathrm{mg} / 8$ hours of ciprofloxacin and 150 $\mathrm{mg} / 6$ hours of vancomycin. This antimicrobial regime was continued for 23 days until the patient was afebrile and had no symptoms synonymous with bacteremia, additional blood cultures were not performed. The child made a complete recovery without complications.

\section{Conclusions}

The first reported human infection with Chromobacterium violaceum was in Malaysia in 1927, and less than 100 cases have been described since [7-10]. This case in Ho Chi Minh City shows the need for rapid diagnosis when there is the suspicion of a puncture wound contaminated with water and soil in tropical regions. A high $\mathrm{C}$ reactive protein, despite having a low specificity, was used as an indicator of severe sepsis. The subsequent early blood culture for isolation, identification and antimicrobial susceptibility were used to diagnose this infection and are essential for initiating early antimicrobial therapy. Although this type of infection is rare it should be factored into the differential diagnosis with Burkholderia spp., Aeromonas spp. and Pseudomonas spp. in tropical and sub-tropical regions, as a substantial delay in treatment can lead to rapid decline and death. We hope that this communication will continue to raise the awareness of this potentially fatal infection and we suggest that the aggressive antimicrobial combination used here is considered when this infection is suspected.

\section{Consent}

Written informed consent was obtained from the patient's parent for publication of this Case report and any accompanying images. A copy of the written consent is available for review by the Editor of this journal. 


\section{Competing interests}

The authors wish to declare that they have no competing interests.

\section{Authors' contributions}

Conceived the study; JIC, JJF, SB, Performed microbiological culturing and identification; JIC, NPHL, LTD, Clinical treatment and antimicrobial therapy; PTQ, NPHL, Drafted manuscript; JIC, SB. All authors read and approved the final manuscript.

\section{Acknowledgements}

We thank the directors and the clinical and microbiology staff of the Hospital for Tropical Diseases, Ho Chi Minh City, for their support in this study. This work was supported by The Wellcome Trust of Great Britain, Euston Road, London, United Kingdom. SB is funded by the OAK foundation through Oxford University.

\section{Author details}

${ }^{1}$ The Hospital for Tropical Diseases, Wellcome Trust Major Overseas Programme, Oxford University Clinical Research Unit, Ho Chi Minh City, Vietnam. ${ }^{2}$ The Hospital for Tropical Diseases, Ho Chi Minh City, Vietnam. ${ }^{3}$ The London School of Hygiene and Tropical Medicine, London, UK.

Received: 18 February 2011 Accepted: 3 January 2013

Published: 4 January 2013

\section{References}

1. Lima-Bittencourt Cl, Astolfi-Filho S, Chartone-Souza E, Santos FR, Nascimento AM: Analysis of Chromobacterium sp. natural isolates from different Brazilian ecosystems. BMC Microbiol 2007, 7:58.

2. Teoh AY, Hui M, Ngo KY, Wong J, Lee KF, Lai PB: Fatal septicaemia from Chromobacterium violaceum: case reports and review of the literature. Hong Kong Med J 2006, 12(3):228-231.

3. Baker S, Campbell II, Stabler R, Nguyen HV, To DS, Nguyen DV, Farrar J: Fatal wound infection caused by Chromobacterium violaceum in Ho Chi Minh City, Vietnam. J Clin Microbiol 2008, 46(11):3853-3855.

4. August PR, Grossman TH, Minor C, Draper MP, MacNeil IA, Pemberton JM, Call KM, Holt D, Osbourne MS: Sequence analysis and functional characterization of the violacein biosynthetic pathway from Chromobacterium violaceum. J Mol Microbiol Biotechnol 2000, 2(4):513-519.

5. CLSI: Performance Standards For Antimicrobial Susceptibility Testing M100-S1 Volume 31 No.1. Clinical and Laboratory Standards Institute: Twenty-first Informational Supplement; 2001.

6. Fantinatti-Garboggini F, Almeida R, Portillo Vdo A, Barbosa TA, Trevilato PB, Neto CE, Coelho RD, Silva DW, Bartoleti LA, Hanna ES, et al: Drug resistance in Chromobacterium violaceum. Genet Mol Res 2004, 3(1):134-147.

7. Ti TY, Tan WC, Chong AP, Lee EH: Nonfatal and fatal infections caused by Chromobacterium violaceum. Clin Infect Dis 1993, 17:505-507.

8. Sneath PHA, Whelan JPF, Singh RB, Edward D: Fatal infection by Chromobacterium violaceum. Lancet 1953, ii:276-277.

9. de Siqueiera IC, Dias J, Ruf H, Ramos EAG, M 163 aciel EAP, Rolim A, Jabur L, Vasconcelos L, Silvany C: Chromombacterium violaceaum in Siblings in Brazil; Emerging Infectious Diseases-www.cdc.gov/eid.vol1, No.9 September 2005.

10. Slesak G, Douangdala P, Inthalad S, Silisouk J, Vongsouvath M, Sengduangphachanh A, Moore CE, Mayxay M, Matsuoka H, Newton PN: Fatal Chromobacterium violaceum septicaemia in northern Laos, a modified oxidase test and post-mortem forensic family G6PD analysis. Ann Clin Microbiol Antimicrob 2009, 8:24.

doi:10.1186/1471-2334-13-4

Cite this article as: Campbell et al: A successful antimicrobial regime for Chromobacterium violaceum induced bacteremia. BMC Infectious Diseases 2013 13:4.

\section{Submit your next manuscript to BioMed Central and take full advantage of:}

- Convenient online submission

- Thorough peer review

- No space constraints or color figure charges

- Immediate publication on acceptance

- Inclusion in PubMed, CAS, Scopus and Google Scholar

- Research which is freely available for redistribution 